\title{
Target Days versus Actual Days of Finished Goods Inventory in Fast Moving Consumer Goods
}

\author{
Anthony Vaz ${ }^{1}$, Shaheen Mansori ${ }^{1}$ \\ ${ }^{1}$ Faculty of Business, Communications and Law, INTI International University, Nilai, Malaysia \\ Correspondence: Anthony Vaz, INTI International University, Room C3-F18, Faculty of Business, \\ Communications and Law, Persiaran Perdana, BBN, Putra Nilai, 71800 Nilai, Negeri Sembilan, Malaysia.
}

\author{
Received: March 24, $2017 \quad$ Accepted: April 21,2017 Online Published: May 4, 2017 \\ doi:10.5539/ibr.v10n6p19 URL: https://doi.org/10.5539/ibr.v10n6p19
}

\begin{abstract}
In a bid to maximize corporate profits, many multi-national corporations and even small medium enterprises create many products and place them on shelves at hypermarkets or supermarkets. We can observe an abundance of stock keeping units on shelves as well as observe a variety of such finished goods held by various fast moving consumer goods industries in the home appliance, beverage, canned food, clothes, soft-drinks, cordials and confectionery product ranges, just to name a few. From supplier, manufacturer, distributor, wholesaler and retailer, it appears that there is a constant flow of new products and stock keeping units held for these fast moving consumer goods. We can say that we humans are a rather wasteful species because a large proportion of products become obsolete or slow moving over time and organizations push products into the marketplace to gain competitive advantage and optimize profits. Hence, there is need to address this issue in the field of Supply Chain Management because resources on this planet are limited and we humans live in a very fragile planet. Yet, as population grows, we humans have become used to this over-abundance even though the resources within this planet are becoming more and more scarce. Consumption levels have increased with population growth and with capitalist thinking, virtually anybody can de velop businesses that will create products to meet human needs. In the field of Supply Chain Management, managers set polices on when to order and how much to order and the average inventory that results from these inventory replenishment policies become targets. This paper attempts to compare target days of inventory with actual days of inventory held in warehouses for a single organization with many warehouses/ stock keeping units, in an attempt to understand further approaches that can be used to improve inventory waste within supply chains.
\end{abstract}

Keywords: average inventory, days cover policies, inventory control systems, order quantities, re-order points, safety stocks, stock in days, usage during lead time

\section{Introduction}

In the fast moving consumer goods (FMCG) industry, many stock keeping units (SKUs) are required to fill the increasing demand for products by humans. If we look at each and every product offered to consumers, many brands in different pack sizes are offered to consumers. These inventory held constitute a huge volume of working capital to organizations and many more end up as waste. In studies on food waste, for example, it was found that as much as around one third of all food produced for human consumption (equivalent to a staggering 1.3 billion tons), is lost or wasted annually, according to the United Nations Environment Program. Supermarket giant Tesco has indicated that it generated almost 30,000 tonnes of food waste in the first six months of 2013, of which, $41 \%$ was made up of bakery items and $21 \%$ from fruits and vegetables (Tesco, 2013). In addition, finished goods held on shelves may become slow moving over time. According to Ganeshan (1999), inventories can cost any where from $20 \%$ to $40 \%$ of inventory value a year so managing them in a scientific manner to maintain minimal levels makes economic sense.

\subsection{Slow Moving Inventory}

There are many reasons why inventory, in particular, finished goods, become slow moving or obsolete over time. Slow moving inventory are inventory that have slowed down in terms of demand. Solomon, Sandborn \& Pecht (2000) found that a product could be classified as obsolete and slow moving when it is nearing the end of its product life cycle. The organization then attempts to significantly reduce design iterations, inventory expenses, sustainment costs, and overall life cycle product costs. Additionally, substitution of products or parts can 
significantly and instantaneously reduce demand for specific items and lead to inventory obsolescence. According to Braglia, Grassi \& Montanari (2004), slow moving and dead inventory items refers to a level of inventory which has either slowed down in demand and consumption or has never gone under the organization's pre-determined level in a given interval of time. Wintle and Patch (2003) have discussed that organizational policies, competing priorities, system support, and staff training have resulted in companies holding inappropriate quantities of slow-moving items. According to Romanies (2016), holding on to bad inventory for years without disposal or write off, will cost an organization investment opportunities, borrowing costs, storage costs, and management costs and it makes the financials look bad. Stock and Lambert (2009) indicated that the obsolescence cost is the difference between the original cost of the unit and its salvage value. Simchi-Levi, Kaminsky \& Simchi-Levi (2009) indicated that obsolescence cost is derived from the risk that an item will lose some its value because of changes in the market. Damages and stock losses related to finished goods are easier to identify than obsolete or dead stock, and firms often focus on finished goods due to their identifiable high value and a higher risk of becoming obsolete. Hung (2000) indicated that policies exist within organizations where year-end accounting policies write off excess inventory as part of presenting a true and fair view of an organization's finances especially for year-end purposes.

As a Supply Chain Manager, two important decisions that need to be made in inventory management for FMCG items are to determine when to order and how much to order. If the Supply Chain Manager gets both these decisions right, product availability and an optimized inventory level will help the organization maximize sales as well as optimize working capital for the organization, therefore reducing inventory waste. Setting when to order and how much to order policies, will also allow the Supply Chain Manager to determine the target days of inventory not only at SKU level but also at group (categories) or total levels.

Table 1 . How inventory is measured

\begin{tabular}{|c|c|}
\hline & Description of inventory measure \\
\hline Volume & Either in sales units, cases, pallets, container loads, weight, length or liters. \\
\hline Value & Sales units multiplied by cost of goods sold or sales price for revenue earned. \\
\hline Turns & $\begin{array}{l}\text { Cost of goods sold / average inventory investment in raw materials, work-in-process \& } \\
\text { finished goods. }\end{array}$ \\
\hline Cover & $\begin{array}{l}\text { Inventory cover in seconds, minutes, days, weeks, months (usually days), usually } \\
\text { determined as the current quantity in stock divided by the anticipated future daily rate of } \\
\text { usage or sales. }\end{array}$ \\
\hline Lead Times & $\begin{array}{l}\text { Length of time taken to obtain or supply a requirement from the time a need is ascertained } \\
\text { to the time the need is satisfied. }\end{array}$ \\
\hline Service Levels & $\begin{array}{l}\text { The actual service level attained in a period, usually the number of times an item is } \\
\text { provided on demand over the number of times the item has been demanded. }\end{array}$ \\
\hline Stock-outs & $\begin{array}{l}\text { Expressed as a percentage of demand not met within the total stock population during a } \\
\text { given period. }\end{array}$ \\
\hline
\end{tabular}

Besides value and volume of inventory, the most common measure of inventory is days cover (Table 1) of inventory in finished goods, sub-assemblies, components or raw material. According to King and King (2015), days cover is widely used because it relates directly to lead time. It allows Supply Chain Managers to decide if inventories are appropriately sized to satisfy the reason for having inventory at that spot in the process. Supply Chain Managers in a bid to reduce the complexity of managing many SKUs, resort to some form of classifying inventory into categories of inventory, hence, inventory replenishment rules can be set for a smaller range of products as opposed to determining the related replenishment levels at each SKU level.

Once days of inventory are established as a target for SKUs or inventory categories or as a total, Supply Chain Managers can compare actual days of inventory with target days, but the task of doing this can be quite complex as there are specific calculations to be routinely done. With the use of Excel spreadsheets, simpler tasks for project management and routine calculations can be determined (Kidman, 2011). For manufacturers whose business models are based on rapid product lifecycles and speed, legacy Enterprise Resource Planning (ERP) systems are used but these can be a bottleneck. Legacy ERP systems are designed for transactional data and delivering order shipment, but these systems aren't capable of scaling to meet the challenges supply chains face today. Hence, the issue of managing large databases of data, particularly 'big data' remains a challenge for Supply Chain Managers today (White, 2014). According to SCM World's latest Chief Supply Chain Officer Report, $64 \%$ of supply chain executives consider big data analytics a disruptive but important technology, setting the foundation for long-term change management in their organizations (Columbus, 2015).

\subsection{Problem Statement}

With economic slowdown a global reality, companies are increasing their efforts to reduce capital requirements 
and find operating efficiencies (Wintle \& Patch, 2003). It is no longer grow at any cost but the cost of generating sales, more specifically return on assets (ROA) with return on investment (ROI) carrying significant weight. As part of the overall effort to become more efficient and compete in tough economic conditions, organizations need to review their approach to inventory management for significant and short-term results. Hence, the discussion on the problem statement in this research looks specifically at how inventory is measured and how we can attempt to reduce inventory held to minimize inventory waste. There has been more emphasis within various industries to improve days cover or inventory turnover performance in make to order versus make for stock environments and the evidence suggests that there is much scope to improve days cover or inventory turnover in make for stock environments.

\subsection{Higher Inventory Turnover (or Days of Inventory) in Make to Order versus Make for Stock Environments}

We can note from the literature that generally, two types of mutually supportive concepts exist for lean (make for stock\} and agile (make to order) manufacturing. Lean manufacturing is appropriate when market conditions are basically stable, demand is smooth and standard products are produced, whereas agile manufacturing is appropriate when the environment is more turbulent and more product variety is present (Vazquez-Bustelo, Avella \& Fernandez, 2007). We can note that in make to order (Just-in-time or JIT) environments, many variables have been researched to determine relationships between JIT manufacturing practices and performance outcomes (Mackelprang \& Nair, 2010). Table 2 shows such variables.

Table 2. Variables to determine relationships between JIT manufacturing practices and performance outcomes

\begin{tabular}{llll}
\hline \multicolumn{2}{l}{ Variables used in make to order environments } & & Kanbanpull system \\
\hline Set-up time reduction & $\begin{array}{l}\text { Multi-function } \\
\text { workers } \\
\text { Small-group problem } \\
\text { Solving }\end{array}$ & Repetitive master schedule & Preventive maintenance \\
JIT deliveries from supplier & $\begin{array}{l}\text { Training } \\
\text { Daily } \\
\text { adherence }\end{array}$ & $\begin{array}{l}\text { Equipment layout } \\
\text { Supplier quality levels }\end{array}$ & Product design simplicity \\
\hline
\end{tabular}

Note. MRP = Material Requirement Planning

However, in make for stock environments, product availability has become the number one priority and in such an environment of high product availability, the probability of waste in the form of obsolete inventory held in warehouses is generally high as outdating values are perceived to be high especially for fresh food (Mertens, 2013). In addition, attempting to push inventory through the distribution network, customer service has become the number one objective with attempts to reduce cost coming a close second. In a study conducted in the US (Table 3), inventory related importance tend to focus on stock-outs, cash flow, inventory turns, lead times, fill rates whereas inventory obsolescence ranked a distant sixth (Fraser \& Brandel, 2007).

Table 3. Ranking of inventory management objective in US study (Fraser \& Brandel, 2007)

\begin{tabular}{ll}
\hline Inventory management objective & Ranking \\
\hline Stock-outs & 1 \\
cash flow & 2 \\
inventory turns & 3 \\
lead times & 4 \\
fill rates & 5 \\
Inventory obsolescence & 6 \\
\hline
\end{tabular}

In another study by Eroglu and Hofer (2011), 54 manufacturing companies in the US showed that the shape of inventory-performance relationship varies considerably across industries. Eroglu and Hofer (2011) began their studies by stating that limited evidence exists for inventory leanness leading to improved firm performance. The Japanese experience of JIT production has shown that there are benefits associated with efforts to reduce inventory lead time and the associated inventory cost (Pan \& Yang, 2000). However, not all products can apply the JIT-in-time strategy because consumers of fast moving consumer goods expect the product to be on the shelf at the time of purchase.

\subsection{Evidence Supports Inventory Turnover Performance is Significantly Poorer in Make for Stock Environment}

In studies by Niu (2013), it was made known that Apple Inc. had the best supply chain in the world for 4 straight years (Figure 1). 


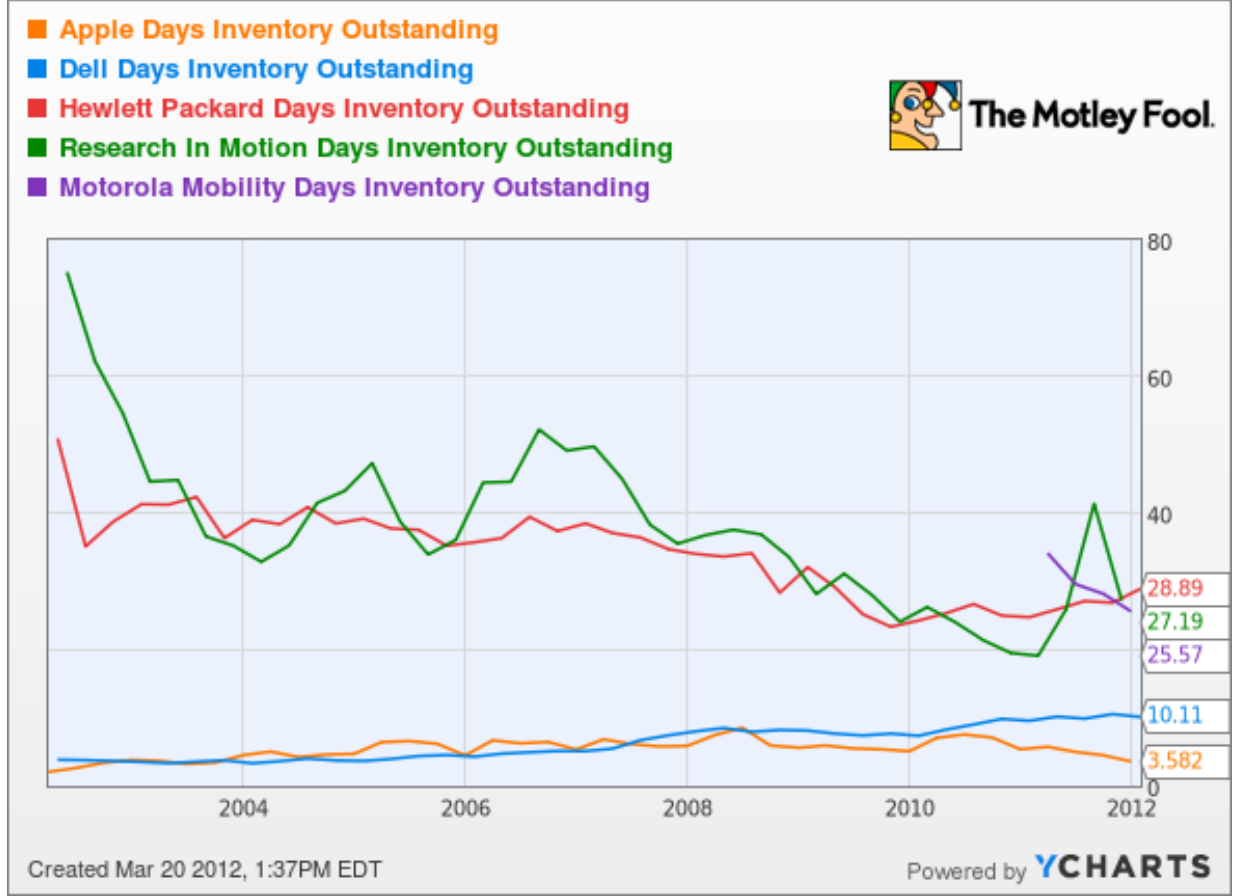

Figure 1. Comparison of inventory Turnover and Days of Inventory (2002-2012)

In Figure 1, we can note that the measures reflect reduced inventory in make to order industries for laptops, smartphones and electronic products, whereas there is much scope for improvements in inventory performance in make for stock industries.

Table 4. Inventory turnover in leading organizations

\begin{tabular}{llll}
\hline & \multicolumn{3}{c}{ Inventory turnover in organizations } \\
\hline Make to order organizations & \multicolumn{4}{c}{ Make for stock organizations } \\
\hline Dell Computer & 90 & Coca-Cola & 14 \\
Nissan & 150 & Home Depot & 5 \\
McDonalds & 112 & Anheuser Busch & 15 \\
& & Johnson Controls & 22 \\
\hline
\end{tabular}

Table 4 shows that organizations that are in make to order environments tend to move their inventory faster than those in make for stock organizations (Heizer \& Render, 2017). Based on comparisons of inventory turnover between these organizations, we can note that there is significantly more inventory in make for stock compared to make to order environments. The main reason for this as explained earlier is that inventory related importance among companies tend to focus on product availability as a main objective (Fraser \& Brandel, 2007) because consumers will not wait for the product when they attempt to make a purchase. Consumers in make to order environments may wait for products after an order has been made, for example in laptop assembly or car manufacture. An exception could be true in the case of McDonalds, where customers are able to wait just long enough in the queue from order of product to receiving the product during drive-ins, in particular.

\section{Literature Review}

The literature review for the area of study attempts to introduce the fast moving consumer goods industry and the scope of inventory held within warehouses in the FMCG business for make for stock type business. This then leads to the literature involving inventory categorization (or classification) which then leads to how inventory categories are used to determine target days of inventory to be compared with actual days of inventory (Stock In Days or SID) held. The mathematical models of inventory management, in particular, those that decide when to order and how much to order are looked at, as these directly impact the amount of days inventory is held in a business. Inventory control systems using fixed order period systems and fixed quantity review system and the calculation of safety stock using desired service levels will also be reviewed to determine when to order. How much to order using days cover policies as well as the economic order quantity (EOQ) and production order quantity (POQ) models will be researched as order quantities form a main part of how much inventory is held. It can be deduced that the bigger the order quantity, the higher the average inventory held. 


\subsection{Inventory Performance and Days of Inventory}

In the study by Oliva and Watson (2011), days of inventory performance was used as a performance measure of operational effectiveness. Actual days of inventory for this study uses the formula:

End period inventory in sales units/ sales units ordered annually multiplied by 365 days

Formula (1) is used to determine days of inventory of finished goods for the fast moving consumer goods business held in warehouses. In financial accounting, the measure of days in inventory (or average turnover period, or days of inventory held) carries the same information as the inventory turns measure (Business Encyclopedia, 2016). Whereas turns is a rate, the SID measure expresses the same information as a number of days per turn. In preparing year-end accounts, analysts usually use 365 days while some analysts prefer 360 and use sales revenue or cost of goods sold divided by average inventory held to determine inventory turnover. However, in this study, the end period sales units divided by the sales units ordered annually is used and obsolete inventory for such businesses will impact days of inventory which impacts warehouse space and working capital if inventory is not carefully managed. To continue with the literature on days of inventory, we need to review literature on inventory control systems and mathematical models used in inventory and how re-order points and order quantities are determined that will impact days of inventory held.

\subsection{Inventory Control Systems}

The managerial procedure for implementing an inventory policy is inventory control. The accountability of control measures units at a specific location and tracks additions and deletions (Bowersox, Closs \& Bixby Cooper, 2010). Inventory is held for a variety of reasons and these could be due to unexpected changes in customer demand, the presence of many situations of a significant uncertainty, lead times or economies of scale offered by transportation companies (Simchi-Levi et al, 2009). Hence, Longo and Mirabelli (2008) suggested the use of a decision making tool and compared the effects of demand versus inventory control policies, lead times, customer's demand intensity and variability in an advanced supply chain management tool based on modeling and simulation. Hence, when inventory is held, inventory control systems are used to control the level of inventory and for the fast-moving consumer goods industry, inventory control systems are usually favored.

\subsection{Mathematical Models Used in Inventory}

The literature states that there are common models that can be found to determine:

- When to order? - the Re-order point ( sometimes called the Re-order level or R)

- How much to order? - the quantity to be ordered (or Q).

These questions will help a Supply Chain Manager to determine the right level of inventory to be held to ensure optimized working capital held in relation to the desired customer service levels required by the market. Knowing when to order and how much to order is determined using inventory control systems. Inventory control systems can be illustrated below using Figure 2 (Krajewski, Ritzman \& Malhotra, 2010).

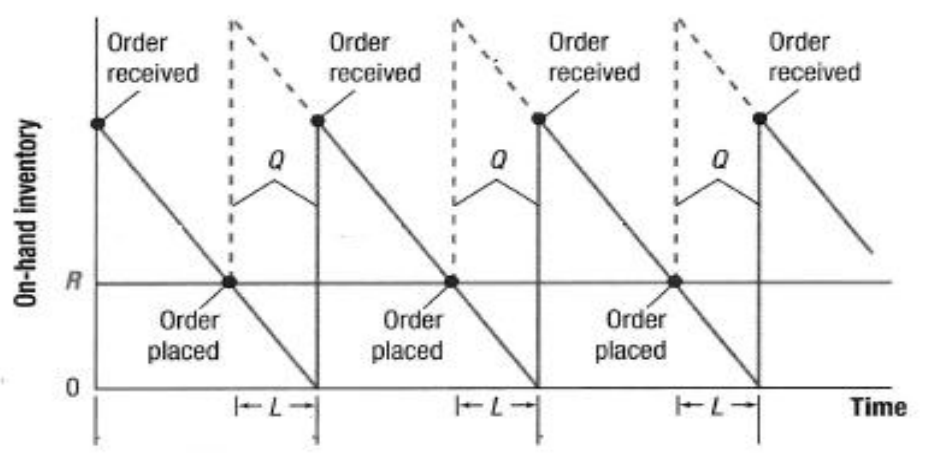

Figure 2. Inventory control system (demand and lead time constant)

Note. $\mathrm{L}=$ Lead time; $\mathrm{R}=\mathrm{Re}$-order level; $\mathrm{Q}=$ Quantity

When inventory reaches a user defined re-order point or level $(\mathrm{R})$, an order $(\mathrm{Q})$ is placed periodically. In the real world today, consistency of demand happens less frequently and so inventory control systems that cater for inconsistent demand have been developed, two of which use the following methods:

- Fixed quantity review system (also called continuous review policy), and 
- $\quad$ Fixed period order system (also called periodic review method)

\subsection{Fixed Quantity Review System}

When demand is uncertain and not constant, the time between orders (TBO) is illustrated in Figure 3 (Krajewski et al, 2010). TBO is not consistent between products and an organization may choose this type of inventory control system and calculate replenishment order quantities based on target days or batch sizes and fix the order quantity over the review period. Simchi-Levi and Kaminsky (2008) suggested that categories of inventory with higher order volume should have a high-frequency continuous review policy (e.g. daily or weekly review) whereas categories with lower order volume should be reviewed using the periodic review method (e.g. monthly or longer).

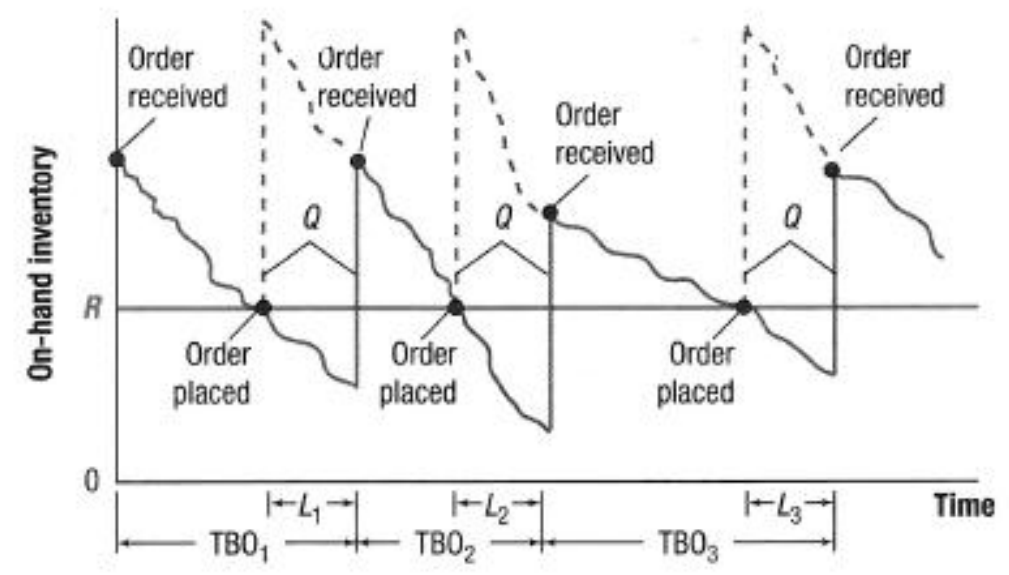

Figure 3. Fixed quantity review system (continuous review)

Note. TBO $=$ Time between orders

\subsection{Fixed Period Order System}

In the fixed period order system, the on-hand inventory is reviewed periodically (usually end-of-month) and could be used for demand that can be lumped periodically for bulk purchases. Quantities (Q) ordered are not fixed but the review period (P) is fixed as per Figure 4 (Heizer \& Render, 2017).

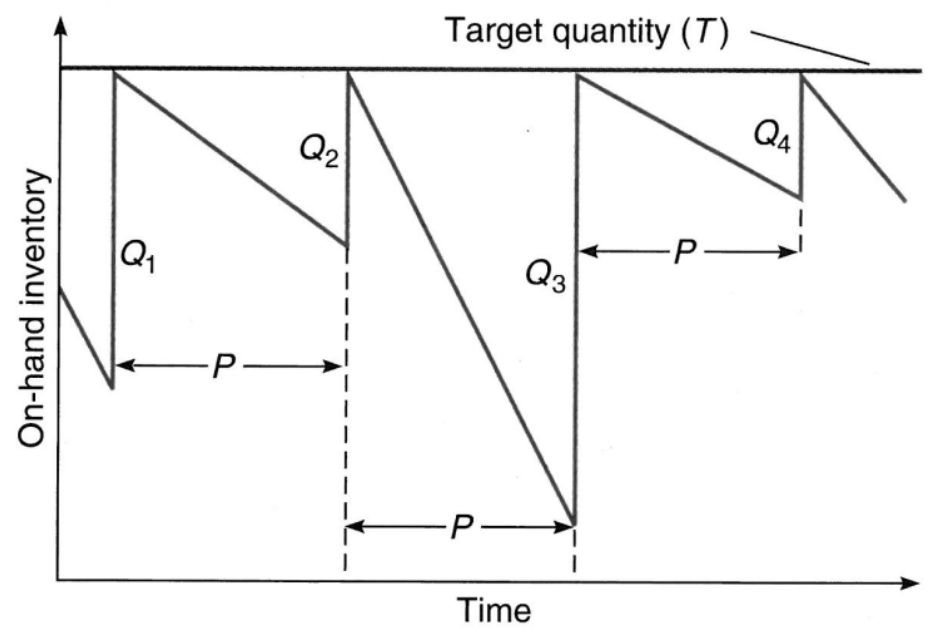

Figure 4. Fixed-period order system

Note. $\mathrm{P}=$ Review period

\subsection{Determining the Re-order Point}

Reid and Sanders (2010) wrote that not all items in the company's inventory are equal and do not need the same level of control. Krajewski et al (2010) wrote that in order to determine when the re-order point is during the lead 
time, the usage during the lead time is determined. Daily usage during the lead time can be firstly determined by dividing annual demand by 365 days. 365 days is used instead of working days (usually about 250 days) because financial statements use 365 days in the determination of days of inventory, irrespective of actual days worked and this is a standard measure in the field of accounting although some analysts prefer 360 days (Business Encyclopedia, 2016). Daily usage is then multiplied by the lead time days to determine R. However, when demand is uncertain, safety stocks are needed to cover fluctuation in demand.

\subsection{Calculating Safety Stocks Using Desired Service Levels}

If no demand fluctuation exists, we can determine $\mathrm{R}$ (or the re-order point) to re-order an item, as the daily average usage multiplied by the lead time in days. In a study, Beamon (1998) looked at setting of safety stock levels using single echelon approximations of lead time, demand and supply variation to achieve a desired inventory performance.

According to Heizer and Render (2017), if the demand fluctuates and a desired service level of say 90\% (or higher) is required, we can use normal distribution tables to determine the Z-score, thus applying :-

Re-Order Point $=$ Average demand during the lead time $+Z$-score multiplied by the standard deviation $(\sigma)$ of the data distribution

The Z-score helps determine a single number that can be applied to the standard deviation (Render, Stair Jr., Hanna \& Hale, 2013) to determine the probability of meeting fluctuating demand.

The standard de viation of the sampling distribution will equal the population standard de viation divided by the square root of the sample size (n).

$$
\sigma_{\bar{x}}=\frac{\sigma_{x}}{\sqrt{n}}
$$

$\sigma_{\bar{x}}$ is the standard deviation of 'x' number of samples

\subsection{How Much to Order?}

In the inventory control system model (Figures 3 and 4), Q is the quantity to order. Several approaches can be made to determine the quantity to order.

- Q determined is based on days cover policies

- Economic Order Quantity model

- Production Order Quantity model

\subsection{Order Quantity Determined Using Days Cover Policies}

This is a general rule of thumb policy that uses days cover policies to determine how much to order. Organizations may order a month's inventory at a time, simply because they pay their creditors monthly payments. This can be considered a weak policy because the $\mathrm{Q}$ ordered will determine the average level of inventory held (Figure 5).

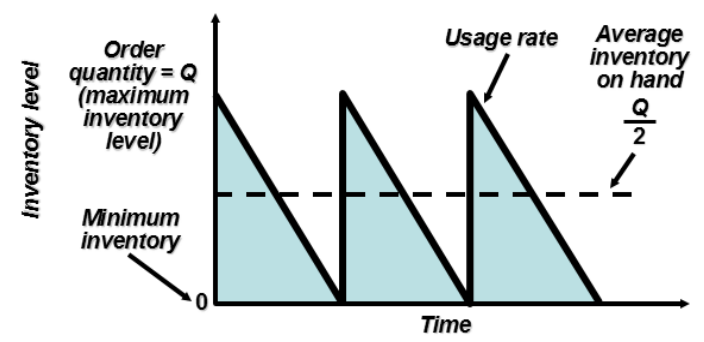

Figure 5. Average inventory is Q ordered divided by 2

When quantities are ordered, average inventory held is determined by the formula:

Average Inventory (or target inventory held $)=Q / 2$

$\mathrm{Q} / 2$, or the midpoint between the time inventory arrives and the time it depletes to zero (if no safety stocks are held) will result in a 2 -week inventory held if 4 weeks of inventory is ordered. In many JIT environments, only a 
few days of inventory is held (for example, Toyota keeps 2-3 days of inventory and Dell keeps about 4-5 days of inventory) whereas in FMCG industries, quantities ordered based on categories may be set at lower days replenishment for items with higher volume as opposed to higher days replenishment for items with lower volume.

\subsection{Economic Order Quantity (EOQ)}

Harris (1915) developed the EOQ model that attempted to equate holding costs and ordering costs. EOQ us es the formula where EOQ is the square root of $2 \mathrm{DxS} / \mathrm{IC}$, where $\mathrm{D}=$ annual demand, $\mathrm{S}=$ setup or ordering costs and I=the holding cost, as a fraction of standard cost (C) of the product. From Figure 6, we can gather that ordering costs tend to increase as we order more frequently. Additionally, the bigger the quantity ordered, the higher the average inventory will be held, since average inventory is determined as Q divided by 2 . Hence, the most economical order quantity occurs when holding costs equate with ordering costs (Heizer \& Render, 2017).

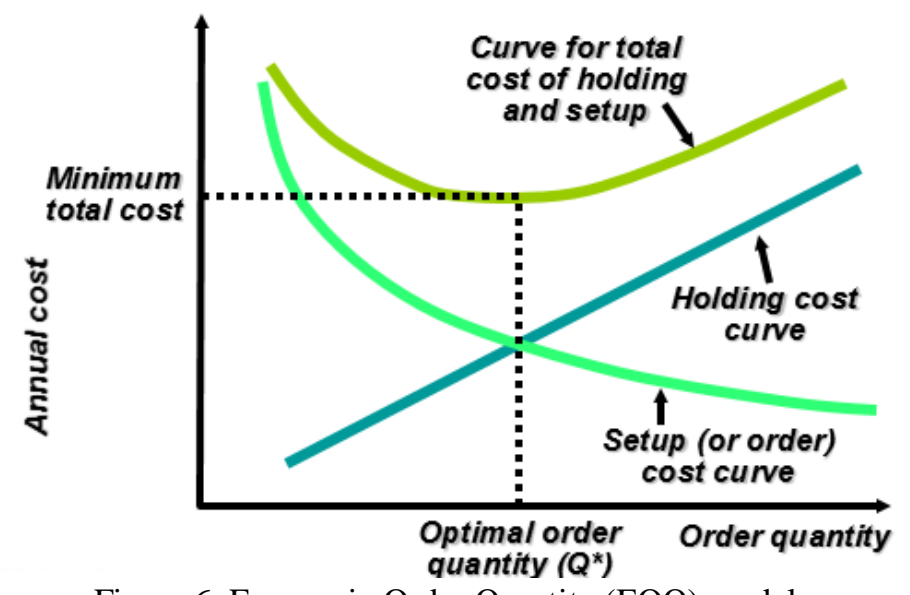

Figure 6. Economic Order Quantity (EOQ) model

EOQ is excellent for use when demand is consistent and stable. Hence, it could be used for replenishment of shelf stock (in a department store) and for re-ordering medical supplies (in a hospital). However, the EOQ model has its limitations, because it assumes that demand is constant throughout the year. In real life, this is hardly so, but some products, example pharmaceutical products purchased monthly by patients undergoing various treatments may exhibit consistent monthly demand patterns.

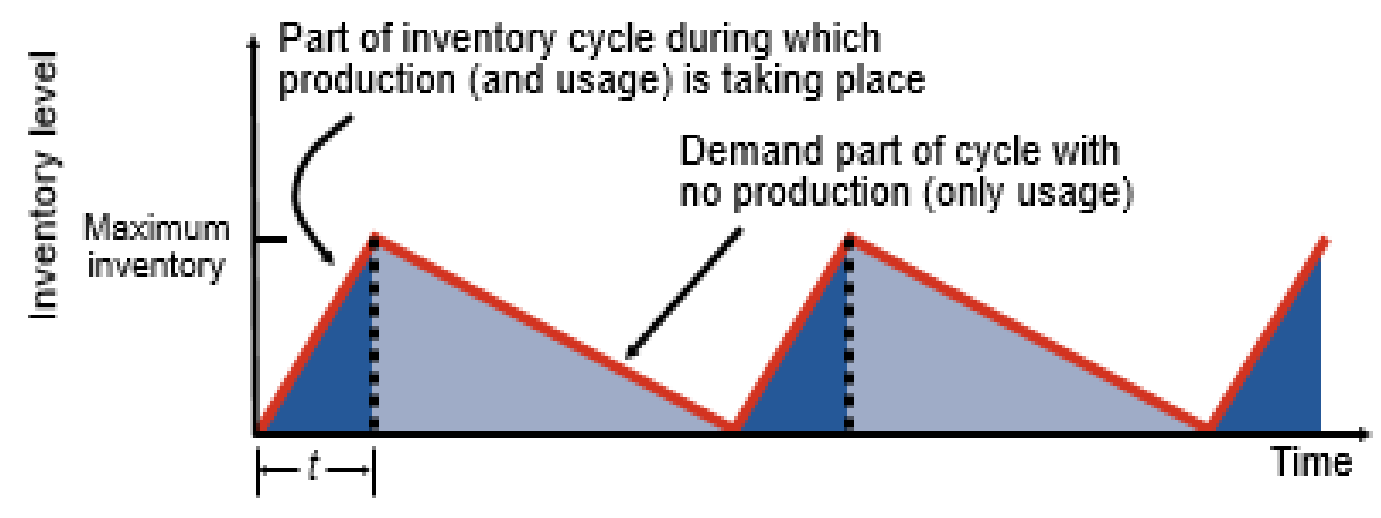

Figure 7. Production order quantity

\subsection{Production Order Quantity (POQ)}

The POQ model is a variation of the EOQ model and is used when units are produced and sold simultaneously. The EOQ model was criticized (Tersine et al, 1999) as the EOQ calculation was considered inappropriate for determination of lot sizes for in-house production. Therefore, holding costs are marginally lower as units produced and sold offset each other by daily production and daily demand (Figure 7). The EOQ formula is thus adjusted to reflect this where the square root of $2 \mathrm{DxS} / \mathrm{IC}$ now becomes the square root of $2 \mathrm{DxS} / \mathrm{IC}(1-\mathrm{d} / \mathrm{p})$ where $\mathrm{d}=$ daily demand and $\mathrm{p}=$ daily production (Heizer \& Render, 2017). 


\subsection{How Much to Order Determines Average Inventory Held}

Earlier, we mentioned that $\mathrm{Q}$ divided by 2 provides us with average inventory held. However, when safety stocks are held, we can determine average (or target) inventory held as:

$$
\text { Safety stocks }+Q \text { ordered } / 2
$$

On average, the level of inventory held based on user defined policies will be the level of safety stock and a point between the minimum and maximum of $\mathrm{Q}$ ( or $\mathrm{Q} / 2$ ).

This then becomes the target inventory and the number of days to be held and the value of the inventory can be calculated. Safety stocks can be set arbitrarily at 2 weeks and set this way when standard deviation data is not readily available. When replenishment policies involving the amount of safety stock to be held are not reviewed regularly, an organization can be out of stock or hold excess inventory.

\subsection{Inventory Categorization}

Inventory categorization attempts to classify inventory into categories. The most common unit of measure used in inventory categorization is order volume and order volume is measured in either sales units, cases, pallets, container loads, weight, length or liters. This study uses:

Order volume as number of orders in sales units received in a year (where $d$ are orders received daily and $\sum d$ is the sum of all ordersfor a stock keeping unit (SKU) during a year)

A popular way of categorizing inventory (Reid \& Sanders, 2010), is to classify volume of sales units by SKUs received into $\mathrm{ABC}$ categories (Figure 8).

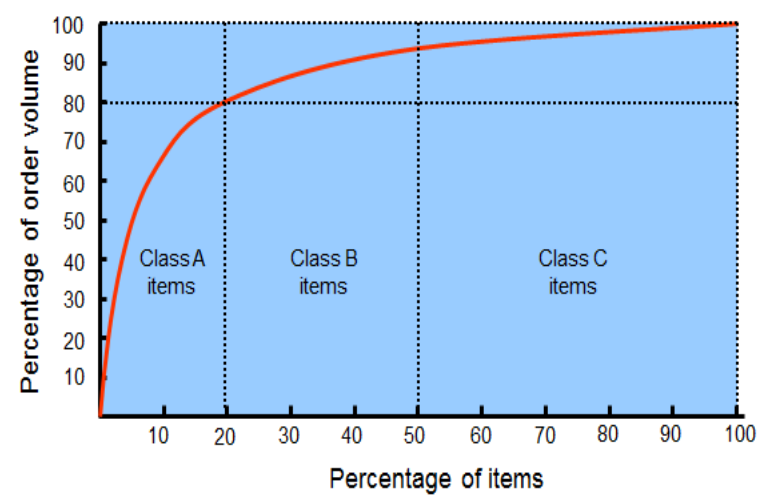

\begin{tabular}{|r|c|}
\hline \begin{tabular}{|} 
Percentage of \\
items
\end{tabular} & Order Volume \\
\hline $20 \%$ & $80 \%$ \\
\hline $30 \%$ & $15 \%$ \\
\hline $50 \%$ & $5 \%$ \\
\hline
\end{tabular}

Figure 8 . ABC classification of inventory, based on the order volume

Usually, as inventory is classified in groups called ABC groupings, Supply Chain Managers attempt to categorize the many number of SKUs into a few categories, so that common replenishment rules can be applied to the few categories.

\subsection{Determining Target Days of Inventory Held Using ABC Analysis}

We can demonstrate how inventory categories are used to determine target days of inventory held. For example, if we use $\mathrm{A}=0$ to $80 \%, \mathrm{~B}=81$ to $95 \%$ and $\mathrm{C}=96$ to $100 \%$, we can determine $\mathrm{ABC}$ categories based on order volume as per Table 5 .

Table 5. How ABC categories are developed

\begin{tabular}{|c|c|c|c|c|c|}
\hline No & Inventory items & $\begin{array}{l}\text { Order } \\
\text { Volume }\end{array}$ & $\begin{array}{l}\text { Cumulative } \\
\text { volume }\end{array}$ & Cumulative percentage & Grade \\
\hline 1 & SKU1 & 50 & 50 & $50 / 100 * 100=50.00 \%$ & $\mathrm{~A}$ \\
\hline 2 & SKU2 & 30 & 80 & $80 / 100 * 100=80.00 \%$ & A \\
\hline 3 & SKU3 & 9 & 89 & $89 / 100 * 100=89.00 \%$ & $\mathrm{~B}$ \\
\hline 4 & SKU4 & 5 & 94 & $94 / 100 * 100=94.00 \%$ & $\mathrm{~B}$ \\
\hline 5 & SKU5 & 3 & 97 & $97 / 100 * 100=97.00 \%$ & $\mathrm{C}$ \\
\hline 6 & SKU6 & 2 & 99 & $99 / 100 * 100=99.00 \%$ & $\mathrm{C}$ \\
\hline \multirow[t]{2}{*}{7} & SKU7 & 1 & 100 & $100 / 100 * 100=100.00 \%$ & $\mathrm{C}$ \\
\hline & Total & 100 & & & \\
\hline
\end{tabular}

Hence, we can determine target days of inventory as per the method below. We begin by looking at average withdrawal rate per day for each $\mathrm{ABC}$ category of inventory (Table 6). 
Table 6. Average withdrawal rate per day for $\mathrm{ABC}$ categories

\begin{tabular}{ll}
\hline Categories & Average withdrawal rate \\
\hline A & 80 units a day \\
B & 14 units a day \\
C & 6 units a day \\
Total & 100 units a day \\
\hline
\end{tabular}

Supply Chain Managers may then set days cover policies for each category as per the parameters set (Table 7).

Table 7. Setting of re-order points (ROP) and order quantities (Q) days cover using inventory categories

\begin{tabular}{lllll}
\hline Category & ROP(days) & Q (days) & ROP (units) & Q (units) \\
\hline A & 7 & 14 & 560 & 1120 \\
B & 14 & 28 & 210 & 420 \\
C & 28 & 84 & 140 & 420 \\
Total & & 910 & 1960 \\
\hline
\end{tabular}

The ROP is usually set based on days of lead time to obtain supplies plus safety stock (in days), usually to cover fluctuations in demand. According to Randall, Nowicki \& Kulkarni ( (2016), the perfect formula for determining the right amount of inventory (also called the Science of theoretical minimums) helps Supply Chain Managers to minimize the level of inventory to optimize customer service, as both working le vel targets and customer service are conflicting in nature. Randall et al (2016) explain that lead time is the physical lead time and informational lead time. Informational lead time can be shortened through the use of technology and IT systems, so usage during the physical lead time and inventory to cover fluctuations in demand can help determine the re-order point for inventory items. Hence, in Theoretical Minimum Modelling (TMM), we can say that the re-order point will be:

Usage during the lead time (lead time in days multiplied by average daily usage) plus safety stocks (to cover the probability of meeting a percentage of total demand, usually about $95 \%$ at least)

Using the data in Tables 5 and 6, we can derive average inventory (or Q/2), as calculated as 1960/2=980 units and in terms of days this is 9.8 days held on average for the inventory policies in the example. If another 1000 units of safety stocks are held, formula for average inventory held will then be $\mathrm{Q} / 2+$ Safety stocks or 19.8 days. Hence, target days of inventory for any given inventory policy can be determined and this can then compared with actual inventory held for management to consider policies that may reduce working capital or improve customer service.

\subsection{The FMCG Industry}

In the FMCG environment (for example, biscuits, soft drinks, ketchups, sauces, canned food, confectionery, snacks, cordials, soaps, detergents, shampoos, etc), finished goods need to be kept to meet the consumers' 'first moment of truth'( $P \& G, 2009)$ when the consumer has intentions to purchase. The second moment of truth is that the product must perform according to its functional feature after the purchase has been made. Therefore, if the product is not available on the shelf when it is about to be purchased, consumers may choose an alternative competitor product. Hence, in the FMCG business, inventory or product availability is a highly desired objective. However, in such an environment of high product availability, the probability of waste in the form of obsolete inventory is high. Various factors such as a slowing down of demand or a change of product specifications, for example, tend to influence such waste and there are problems associated with managing large amounts of stock keeping units within the fast moving consumer goods business which could lead to obsolete inventory, which are costs to an organization.

\subsection{Warehouse Stock Keeping Units}

In the fast moving consumer goods industry, warehouses are used by manufacturers and distributors to hold stock keeping units as an interface between the customer and the manufacturer. Since lead times vary between warehouses and manufacturers, inventory are held with the objective of meeting customer demand as it arrives. According to Simchi et al (2009), due to longer lead times and demand uncertainty, manufacturers tend to employ a push strategy and fill warehouses in anticipation of demand. A study on traditional arborescent supply chains tend to show a central warehouse supplying regional distribution centers who ultimately supply their customers (Figure 9). 


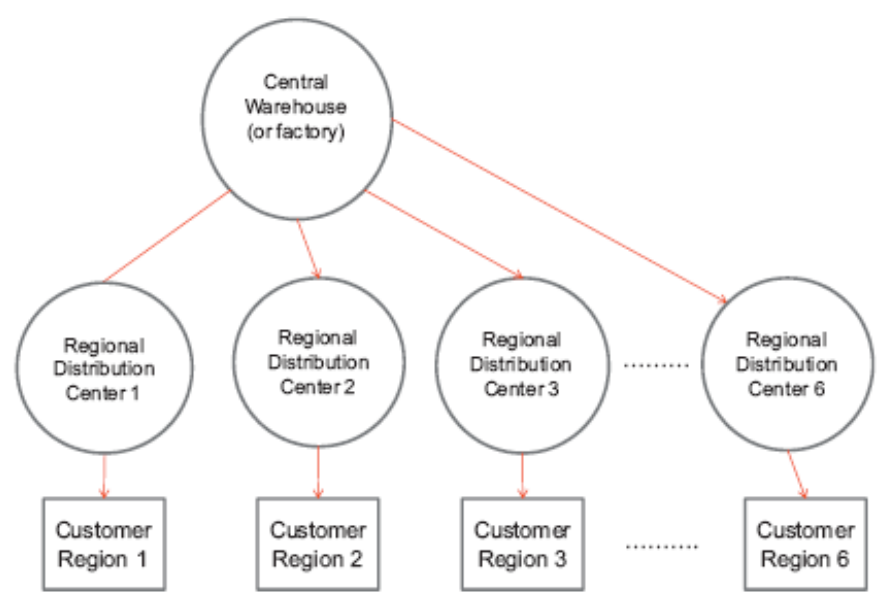

Figure 9. Traditional arborescent supply chains

The study by Cattani, Jacobs \& Schoenfelder (2011) shows that there are weaknesses with this outbound supply chain structure. The system assumes a central warehouse supplies second-tier warehouses who serve uniquely defined regional customers. Cattani et al (2011) found that such multi-echelon systems do not achieve inventory optimization. On the other hand, a suggested single-echelon system (Figure 10) that considers a dual role central warehouse is preferred where the central warehouse supplies both regional and serves customers in the local region.

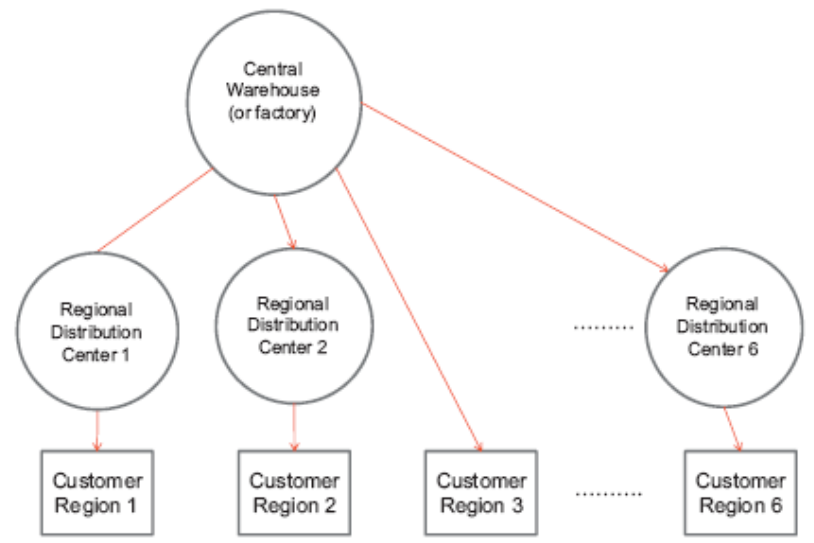

Figure 10. A supply chain with a dual role central warehouse

This study will look at days of inventory within the many warehouses in an organization and compare days of inventory held versus target days. The objective is to consider the potential reasons for the difference and to make recommendations as to how to improve the variance.

\section{Research Methodology}

A simulation consisting of order volume for $\mathrm{ABC}$ categories and inventory parameters will provide a target days cover of finished goods inventory which can then be compared with actual on-hand days cover of inventory. The comparison will yield many results that will consider differences that could explain whether inventory held could be lowered to meet working capital targets or increased to meet customer service objectives. Based on the literature, a simulation-based optimization framework involving simultaneous perturbation stochastic approximation (SPSA) is usually presented as a means for optimally specifying parameters of internal model control (IMC) and model predictive control (MPC) based decision policies for inventory management in supply chains under conditions involving supply and demand uncertainty (Schwartz, Wang \& Rivera, 2006). The effective use of the SPSA technique serves to enhance the performance and functionality of this class of decision algorithms and is illustrated with case studies of actual data involving the simultaneous optimization of controller tuning parameters and safety stock levels for supply chain networks. Original studies were inspired from semiconductor manufacturing but this study looks at a fast moving consumer goods organization. The results of the simulation will demonstrate the comparison of days cover target versus actual days of inventory held so that conclusions can be drawn. 


\subsection{Using Case Study Datafor Inventory Modelling}

While the structured questionnaire seems to be most popular with most researchers (Viera, Yoshizaki \& Ho, 2009), much research into the area of supply chain and inventory management have used different approaches such as field data collection, interviews with supply chain practitioners, personal experience (Godsell \& van Hoek, 2009), cited in Brandenburg (2013) as well as the case study approach. This study considers a case study approach and according to Adebanjo, a single-case study research (2009) provides a statistical framework for making inferences from quantitative case-study data. In this study, a single case study will provide the researcher with the whole spectrum of order and inventory records for further analysis. Childe (2011) notes that there is research value of case reports of industries or operations management in practice. For example, from case reports, since the Industrial Age, many theories have continued to provide manufacturers with leading models and applications in the areas of inventory management, such as which items to make for stock or made to order, when to order and how much to order systems. In this study, the various formulas mentioned, will be used in spreadsheet modeling to derive the Theoretical Minimum of inventory to be held and 'what-if' finished goods simulation results (target days of inventory) will be used to make comparisons with actual inventory. To support this study, one-year of order volume data and a snapshot of inventory held will be used. A similar study (Hung Lau, 2012) also used 1 year of sales data in attempting to analyze demand management for downstream wholesale and retail distribution. The organization in this study is a FMCG manufacturer and distributor. The organization operates 28 warehouses and distributes the many SKUs on offer to wholesalers, retailers and even directly to supermarkets and hypermarkets. Order volume is based on annual orders received and inventory held is a snapshot of inventory in the 28 warehouses that it operates from.

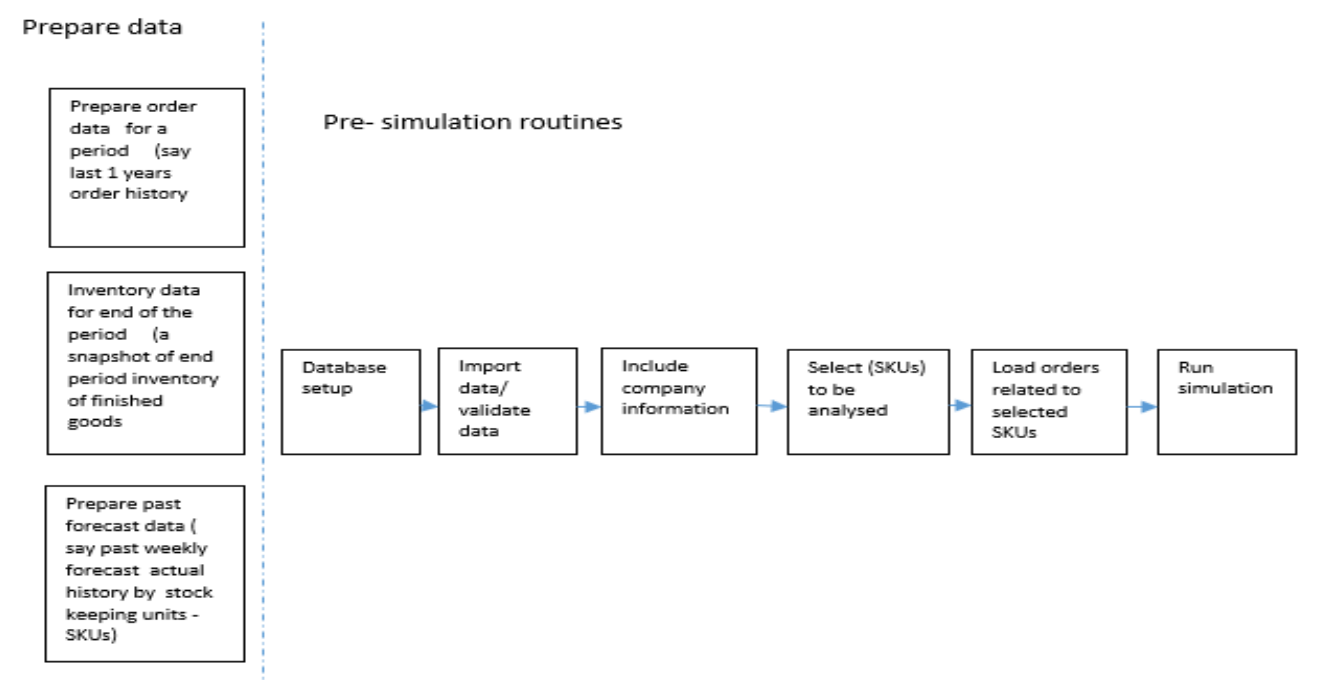

Figure 11. Process of data collection for developing a simulation

Table 8 . A set of inventory parameters used to develop a scenario for inventory simulation

\begin{tabular}{lllllll}
\hline Categories & \% of volume & $\begin{array}{l}\text { ROP } \\
\text { Lead time (days) }\end{array}$ & Safety stocks (days) & Q1 & $\begin{array}{l}\text { Q2 } \\
\text { (days) }\end{array}$ & Q3 \\
\hline A & & 2 & 14 & 14 & 10 & 7 \\
B & Next 15\% & 2 & 14 & 31 & 24 & 16 \\
C & Next 5\% & 2 & 14 & 62 & 48 & 31 \\
Average & & & & 22.2 & 18.8 & 17.8 \\
inventory(days) & & & & & & \\
\hline
\end{tabular}

3.2 Process of Data Collection

The data will be collected using the process in Figure 11. This will allow the researcher to determine target days of inventory versus actual days for each warehouse.

\subsection{Target Days versus Actual Days of Inventory by Warehouse}

To determine the target days of inventory held, the organization under study used the following 3 inventory parameters (Table 8) to determine quantities to be manufactured (Q1, Q2 \& Q3).

It was found that quantities to be manufactured against policy Q2 was suitable to be employed because installed capacity for a key process was found to be sufficient for quick replenishment when required. This is an important point in choosing a suitable inventory policy because the lead time policy of 2 days from receipt of order 
quantities to be manufactured meant no queues if capacity were sufficient (Figure 12).

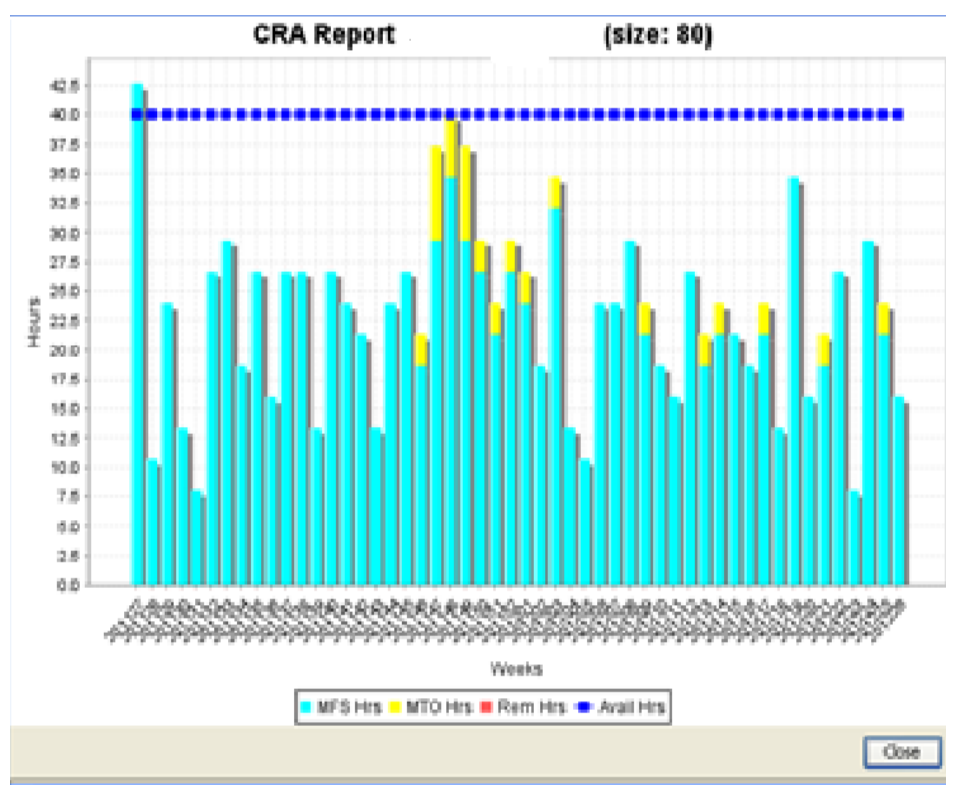

MFS Hrs = Manufacturing hours need to manufacture MFS finished goods items.

MTO Hrs = Manufacturing hours need to manufacture MTO finished goods items.

Rem Hrs = Manufacturing hours need to manufacture remaining (Rem) MFS and MTO finished goods items.

Avail Hrs = Manufacturing hours available. In this illustration, the organization has installed 40 hours of manufacturing capacity which is equivalent to one 8 -hour shift for 5 days a week.

Figure 12. Installed capacity compared to anticipated demand for a key process

Table 9. Target days versus actual days of inventory by warehouse

\begin{tabular}{lll}
\hline & Target SID & Actual SID \\
\hline Warehouse & & \\
W001 & 18.37 & 34.01 \\
W002 & 18.55 & 21.63 \\
W003 & 17.53 & 17.6 \\
W004 & 18.60 & 28.11 \\
W005 & 18.45 & 17.33 \\
W006 & 19.13 & 21.88 \\
W007 & 19.46 & 25.26 \\
W008 & 18.68 & 26.16 \\
W009 & 19.40 & 18.5 \\
W010 & 18.59 & 16.1 \\
W011 & 19.13 & 12.86 \\
W012 & 19.61 & 17.04 \\
W013 & 18.57 & 27.1 \\
W014 & 19.23 & 22.23 \\
W015 & 18.64 & 19.24 \\
W016 & 18.84 & 25.57 \\
W017 & 18.89 & 16.48 \\
W018 & 19.02 & 40.66 \\
W019 & 19.94 & 24.36 \\
W020 & 17.64 & 17.83 \\
W021 & 18.98 & 25.65 \\
W022 & 19.47 & 9.84 \\
W023 & 19.26 & 25.29 \\
W024 & 18.76 & 21.15 \\
W025 & 19.64 & 29.12 \\
W026 & 18.30 & 29.8 \\
W027 & 18.43 & 27.75 \\
W028 & 18.64 & 10.64 \\
\hline The chosen & 15.64 \\
\hline
\end{tabular}

The chosen policy was then compared to the Actual SID and the results are shown in Table 9.

3.5 T-Test

To test the effectiveness of the chosen policy, the following hypothesis has been tested:

$\mathrm{H}_{0}: \mu$ Actual SID $\leq \mu$ Scenario SID

$\mathrm{H}_{1}: \mu$ Actual SID $>\mu$ Scenario SID

Based on the findings from Table 10, we can conclude that the variance of Scenario SID is significantly lower 
than the variance of Actual SID and as calculated, the p-value is less than 0.05.

Table 10.t-Test: Two-Sample Assuming Unequal Variances

\begin{tabular}{lrr}
\hline F-test ( p-value= 0.0001) & & \\
\multicolumn{3}{c}{$\begin{array}{c}\text { Target Stock in days versus Actual Stock in days } \\
\text { Target SID Scenario Q (A=10, B=24, C=48 days) }\end{array}$} \\
\hline Mean & Scenario SID & Actual SID \\
\hline Variance & 18.84821429 & 22.47107143 \\
Observations & 0.313518915 & 47.93498029 \\
Hypothesized Mean Difference & 28 & 28 \\
df & 0 & 27 \\
t Stat & -2.75986806 \\
P(T<=t) one-tail & 0.005130239 \\
t Critical one-tail & 1.703288446 \\
P(T<=t) two-tail & 0.010260477 \\
t Critical two-tail & 2.051830516 \\
\hline
\end{tabular}

The $\mathrm{P}(\mathrm{F}<=\mathrm{f})$ one tail values is less than 0.025 and the $\mathrm{P}(\mathrm{T}<\mathrm{t})$ two-tail values is less than 0.05 . Hence, we can conclude that there are statistically significant differences between the Target SID and Actual SID in this study.

\section{Discussion}

Based on the initial findings, the actual days of inventory held at 22.47 days is $21.1 \%$ higher than the target of 18.85 days. Thereby we can conclude that there are significant differences between the target and actual days of inventory held. Further discussions with the management of the organization showed that the process of inventory planning can be further improved on. Quantities ordered can be reviewed so that lower quantities can be considered since quantity ordered directly impacts average inventory held but sufficient small batch capacity must be installed. Re-order points can also include scientific methods of determining safety stocks, so that the probability of meeting demand will optimize levels of inventory held and meet incoming demand for less stock outs. One other reason given in the discussions was that inventory was at the wrong place when demand arrived. Perhaps, keeping inventory in a centralized warehouse would help improve this.

\section{Limitations and Future Research}

This study attempts to consider how target days are computed in inventory management and how they can be compared to actual days of inventory so as to determine how well Supply Chain Managers are managing finished goods inventory in fast moving consumer goods businesses. The field of Sales and Operations Planning (S\&OP) which attempts to balance demand with supply covers a broader area involving forecasting, inventory categorization, inventory replenishment, material requirement planning as well as capacity and procurement planning. There is much scope to expand this study to include many other factors and therefore a major limitation of the study is that it does not cover the full scope of the Sales and Operations planning process. In addition, the study only covers one organization with multiple warehouses and did not cover broader industry players. Furthermore, in forecasting, many short term forecasting approaches may be considered and in inventory categorization, other variables in addition to order volume may also provide the Supply Chain Manager with additional variables that may allow different alternatives on which items to make for stock or make to order. But, the value of this study needs to be appreciated because at the heart of inventory management, a Supply Chain Manager could use the findings in this study to determine targets and compare them with actual inventory and based on the comparisons, the Supply Chain Manager may consider strategies to lower inventory, taking into account the growing cost of holding inventory with the aim of reducing slow moving and inventory waste.

\section{References}

Adebanjo, D. (2009). Understanding demand management challenges in intermediary food trading: a case study. Supply Chain Management: An International Journa1, 14(3), 224-233. https://doi.org/10.1108/13598540910954566

Beamon, B. M. (1998). Supply chain design and analysis: Models and methods, International Journal of Production Economics, 55(3), 281-294. https://doi.org/10.1016/S0925-5273(98)00079-6

Bowersox, D. J., Closs, D. J., \& Bixby, C. M. (2010). Supply Chain Logistics Management (3rd ed.). McGraw Hill International Edition.

Braglia, A., Grassi, A., \& Montanari, R. (2004). Multi-attribute classification method for spare parts inventory management. Journal of Quality in maintenance Engineering, 10(1), 55-65. https://doi.org/10.1108/13552510410526875 
Brandenburg, M. (2013). Quantitative models for value-based Supply Chain Management. In Supply Management Research, 149-172. Springer Fachmedien Wiesbaden. https://doi.org/10.1007/978-3-658-03061-2_7

Business Encyclopedia. (2016). Inventory, Inventory Management and Accounting explained, Building the business case analysis. https://www.business-case-analysis.com/inventory.html [Accessed on July 9, 2016].

Cattani, K. D., Jacobs, F. R., \& Schoenfelder, J. (2011). Common inventory modeling assumptions that fall short: Arborescent networks, Poisson demand, and single-echelon approximations. Journal of Operations Management, 29(5), 488-499. https://doi.org/10.1016/j.jom.2010.11.008

Childe, S. J. (2011).Case studies in Operations management. Production planning \& control, 22(2), 107. https://doi.org/10.1080/09537287.2011.554736

Columbus, L. (2015). Ten big ways big data is revolutionizing supply chain management. http://www.forbes.com/sites/louiscolumbus/2015/07/13/ten-ways-big-data-is-revolutionizing-supply-chainmanagement/\#1 fe 1945f3d38 [Accessed on 16.7.2016]

Columbus, L. (2015). Ten ways big data is revolutionizing supply chain management. Forbes, July, 13.

Eroglu, C., \& Hofer, C. (2011). Lean, leaner, too lean? The inventory-performance link revisited, Journal of Operations Management, 29(4), 356-369. https://doi.org/10.1016/j.jom.2010.05.002

Fraser, J., \& Brandel, W. (2007). Demand driven inventory management strategies: Challenges \& opportunities for distribution-intensive companies. Industry Directions, Inc.

Ganeshan, R. (1999). Managing supply chain inventories: A multiple retailer, one warehouse, multiple supplier model. International Journal of Production Economics, 59(1-3), 341-354. https://doi.org/10.1016/S0925-5273(98)00115-7

Godsell, J., \& van Hoek, R. (2009). Fudging the supply chain to hit the number: five common practices that sacrifice the supply chain and what financial analysts should ask about them. Supply Chain Management: An International Journal, 14(3), 171-176. https://doi.org/10.1108/13598540910954511

Harris, F. W. (1915). What quantity to make at once. The Library of Factory Management, 47-52. Operation and Costs. Chicago: AW Shaw Company.

Heizer, J., Render, B., \& Munson, C. (2017). Operations management. Sustainability and supply chain management (12th ed.), New Jersey: Prentice Hall.

Hung, L. H., (2012). Demand management in downstream wholesale and retail distribution: a case study. Supply Chain Management: An International Journal, 17(6), 638-654. https://doi.org/10.1108/13598541211269247

Hung, M. (2000). Accounting standards and value relevance of financial statements: An international analysis, Journal of Accounting and Economics, 30(3), 401-420. https://doi.org/10.1016/S0165-4101(01)00011-8

Kidman, A. (2011). Use this Excel spreadsheet for project management. http://www.lifehacker.com.au/2011/12/use-this-excel-spreadsheet-for-project-management [Accessed July 9, 2016]

King, L. K., \& King, J. S.(2015). Value stream mapping for the process industries. Creating a roadmap for lean transformation. CRC Press, Taylor \& Francis Group.

Krajewski, L. J., Malhotra, M. K, \& Ritzman, L. P. (2013). Operations management: Processes and value chains, (10th ed). Pearson Education International.

Longo, F., \& Mirabelli, G. (2008). An advanced supply chain management tool based on modelling and simulation, Computers \& Industrial Engineering, 54(3), 570-588. https://doi.org/10.1016/j.cie.2007.09.008

Mackelprang, A. W., \& Nair, A. (2010). Relationship between just-in-time manufacturing practices and performance: A meta-analytic investigation. Journal of Operations Management, 28(4), 283-302. https://doi.org/10.1016/j.jom.2009.10.002

Mertens, P. A. J., TU, M. U., den Hartog, O. C., Linders, J., \& Jaspers, H. (2016). Waste Reduction in a Distribution Inventory System by Reconsidering Policies in the Central Warehouse.

Niu, E. (2013) Apple lesson of the day: Inventory is evil. http://www.fool.com/investing/general/2012/03/23/apple-lesson-of-the-day-inventory-is-evil.aspx [Accessed on June 29, 2016]. 
Oliva, R., \& Watson, N. (2011). Cross-functional alignment in supply chain planning: A case study of sales and operations planning, Journal of Operations Management, 29(5), 434-448.

https://doi.org/10.1016/j.jom.2010.11.012

P\&G, (2009). Consumer Interaction: $P \& G$ 's two moments of truth. [Video online] Available at http://www.youtube.com [Accessed January 2, 2012].

Pan, C. J., \& Yang, J. (2002). A study of an integrated inventory with controllable lead time. International Journal of Production Research, 40(5), 1263-1273. https://doi.org/10.1080/00207540110105680

Randall, W. S., Nowicki, D. R., \& Kulkarni, S. (2016). The perfect formula for developing the right amount of inventory.

http://www.supplychain247.com/article/the_perfect_formula_for_determining_the_right_amount_of_invent ory [Available at July 12,2016].

Reid, R. D., \& Sanders, N. R.(2010). Operations Management: An Integrated Approach, International Student Version (4th ed.). Hoboken, NJ: Wiley.

Render, B., Stair Jr., R. M., \& Hanna, M. E. (2014). Quantitative analysis for management, Global Edition, Pearson.

Romanies, M. (2016). Disposing of obsolete and excess inventory could be your most profitable sale. Available at:

https://www.allbusiness.com/disposing-of-obsolete-and-excess-inventory-could-be-your-most-profitable-sal e-11661537-1.html [Accessed June 30, 2016].

Schwartz, J. D., Wang, W., \& Rivera, D. E. (2006). Simulation-based optimization of process control policies for inventory management in supply chains. Automatica, 42(8), 1311-1320. https://doi.org/10.1016/j.automatica.2006.03.019

Simchi-Levi, D., Kaminsky, P., \& Simchi-Levi, E. (2008). Designing and managing the supply chain: Concepts, strategies and case studies (3th ed.). McGraw-Hill International Edition.

Solomon, R., Sandborn, P. A., \& Pecht, M. G. (2000). Electronic part life cycle concepts and obsolescence forecasting. IEEE Transactions on Components and Packaging Technologies, 23(4), 707-717. https://doi.org/10.1109/6144.888857

Stock, J. R., \& Lambert, D. M. (2009). Strategic Logistics Management $\left(4^{\text {th }}\right.$ ed.). McGraw-Hill.

Tersine, R. J., Barman, S., Morris, J. S. (1992). A composite EOQ model for situational decomposition, Computers and Industrial Engineering, 22(3), 283-295. https://doi.org/10.1016/0360-8352(92)90006-6

Tesco. (2013). Tesco says almost 30,000 tonnes of food 'wasted' http://www.bbc.com/news/uk-24603008 [Accessed 9th July 2016).

Vazquez-Bustelo, D., Avella, L., \& Fernandez, E. (2007). Agility driver, enablers and outcomes, International Journal of Operations and Production Management, 27(12), 1303-1332.

Viera, J., Yoshizaki, H., \& Ho, L. (2009). Collaboration intensity in the Brazilian supermarket chain. Supply Chain Management: An International Journal, 14(1), 11-21. https://doi.org/10.1108/13598540910927269

White, D. (2014). Dealing with supply chain big data, Available at: https://logisticsviewpoints.com/2014/12/02/dealing-with-supply-chain-big-data [Accessed June 29, 2016]

Wintle, F., \& Patch, W. (2003) Slow-moving inventory: all dressed up and nowhere to go, http://www.inboundlogistics.com/cms/article/slow-moving-inventory-all-dressed-up-and-nowhere-to-go [Accessed on July 16,2016]

\section{Copyrights}

Copyright for this article is retained by the author(s), with first publication rights granted to the journal.

This is an open-access article distributed under the terms and conditions of the Creative Commons Attribution license (http://creativecommons.org/licenses/by/4.0/). 